\title{
LOS DELITOS DE INCITACIÓN AL ODIO EN TIEMPOS DEL COVID-19
}

\author{
Alberto José Ferrari Puerta \\ Departamento de Derecho Internacional, \\ Eclesiástico y Filosofía del Derecho \\ Instituto Universitario de Ciencias \\ de las Religiones. Facultad de Derecho \\ Universidad Complutense de Madrid \\ alferrar@ucm.es \\ Víctor SALCEDO ANTOLÍN \\ Graduado en Derecho por la \\ Universidad Complutense de Madrid \\ Máster en Acceso a la Abogacía \\ Universidad de Alcalá de Henares \\ victorsalcedo.antolin@gmail.com \\ Daniel SimAnCAS SÁNCHEZ \\ Departamento de Derecho Constitucional \\ Facultad de Derecho \\ Universidad Complutense de Madrid \\ dsimanca@ucm.es
}

In memoriam Carmen Piquero Hernández, víctima del Covid-19 e incapaz de odiar a ningún ser humano.

\section{INTRODUCCIÓN}

«Es Shanghai, sigue siendo Shanghai, pero aparece extrañamente oscura y vacía. Las luces de neón se han apagado, los coches no circulan por las calles, los barcos no surcan por el río... y no hay nadie por las calles. Nadie» ${ }^{1}$. Este fragmento de la obra de Laura Gallego Dos velas para el diablo pertenece a un pasaje del libro en el que se relata una visión acerca de un mortífero virus que se transmite por el aire y que tiene consecuencias funestas para la humanidad. Aunque la obra pertenezca al género de la literatura fantástica, por desgracia la espantosa visión relatada en sus páginas se ha hecho realidad a lo largo de estos meses: la pandemia del coro-

\footnotetext{
${ }^{1}$ L. Gallego García Dos velas para el diablo, Madrid, SM, 2008, p. 207.
} 
navirus ha acarreado consecuencias trágicas en todo el mundo ${ }^{2}$ y su repercusión ha trascendido el ámbito sanitario, afectando a prácticamente todas las dimensiones de nuestra vida.

Especialmente trascendentes han sido las repercusiones de la pandemia en el ámbito jurídico, las cuales no han estado exentas de polémica: en el caso concreto de España, numerosos juristas pusieron en duda la idoneidad de la declaración del estado de alarma para la suspensión de derechos fundamentales ${ }^{3}$ (concretamente, del derecho a la libertad ambulatoria del art. $17 \mathrm{CE})^{4}$. Asimismo, la aplicación durante dicho estado excepcional de la Ley Orgánica 4/2015, de 20 de marzo, de Protección de la Seguridad Ciudadana (LOPSC), fue tildada de desproporcionada por algunos autores 5 . Por otra parte, algunos académicos y operadores jurídicos criticaron el lenguaje belicista utilizado por las autoridades civiles y militares en las comparecencias públicas durante las primeras semanas de la pandemia ${ }^{6}$.

En este contexto de aplicación excepcional del Derecho se enmarca el objeto de nuestro artículo, que consiste en el estudio de las denuncias o acusaciones por el delito de incitación al odio del art. 510 del Código Penal (en adelante, CP) durante la vigencia del primer estado de alarma nacional derivado de la crisis del coronavirus. Así, analizaremos tanto las denuncias interpuestas por la Policía o por particulares como las acusaciones formuladas por la Fiscalía o por acusaciones particulares o populares contra hechos acaecidos entre los días 15 de marzo y 21 de junio de 2020, para dilucidar si los hechos que fueron objeto de dichas acusaciones pueden subsumirse dentro del art. 510 a tenor de la interpretación doctrinal y jurisprudencial del mismo o si, por el contrario, carecen de fundamento sólido.

${ }^{2}$ Sobre la falta de previsión frente a la pandemia a nivel global, no podemos sino recordar la profética frase de Albert Camus en su obra La peste: «Ha habido en el mundo tantas pestes como guerras. Y aun así, las pestes y las guerras pillan a todo el mundo desprevenido». Vid. A. CAmus, La peste, Buenos Aires, Editorial Sudamericana, 1979, p. 35.

3 Cerrado este artículo, el Tribunal Constitucional, en su Sentencia 148/2021, de 14 de julio, ha declarado inconstitucionales algunos artículos del Real Decreto 463/2020, de 14 de marzo, por el que se declaró el primer estado de alarma como consecuencia de la pandemia. Entiende el Tribunal que la suspensión de derechos que imponían dichos preceptos exigía la declaración del estado de excepción.

${ }^{4}$ F. J. Álvarez GarCía «Estado de alarma o de excepción», Estudios Penales y Criminológicos, núm. 40 (2020), pp. 1143-1163.

5 C. A. Amoedo-Souto, «Vigilar y castigar el confinamiento forzoso. Problemas de la potestad sancionadora al servicio del Estado de alarma sanitaria», El Cronista del Estado Social y Democrático de Derecho, núm. 86-87 (2020), pp. 66-77.

6 P. Francés LeCumberRI, «Expresiones punitivas en la emergencia de la Covid-19», en I. Rivera Beiras (coord.), Pandemia. Derechos bumanos, sistema penal y control social (en tiempos del coronavirus), Valencia, Tirant lo Blanch, 2020, pp. 98-99. 


\section{EL ODIO DISCRIMINATORIO EN TIEMPOS DE EPIDEMIA: UNA CONSTANTE HISTÓRICA}

«Los prejuicios [...] al menos desde Allport, son el humus en el que se asienta la teoría y práctica de la discriminación» ${ }^{7}$. Esta afirmación del profesor Javier de Lucas coincide con la mayoría de los académicos y profesionales especializados en materia de delitos de odio: el origen del odio discriminatorio radica en el prejuicio. Gordon Allport, psicólogo estadounidense, definió el concepto de prejuicio como «una actitud hostil o prevenida hacia una persona que pertenece a un grupo, suponiéndose, por tanto, que posee las cualidades objetables atribuidas al grupo» ${ }^{8}$. Si desmenuzamos el concepto de prejuicio, podemos encontrar tres componentes dentro del mismo: uno cognitivo, que viene dado por los estereotipos, una suerte de esquemas mentales que presentan una visión simplificada de un colectivo; uno afectivo, que consiste en la suscitación, como consecuencia de esa visión simplista del colectivo, de una serie de sentimientos, normalmente negativos, como el miedo o la aversión; y uno conativo, que es la propensión a llevar a cabo conductas hostiles o discriminatorias hacia ese grupo?.

En tiempos de epidemia, de sentimiento de miedo generalizado, de desconfianza hacia el prójimo ${ }^{10}$, suele ser frecuente la exacerbación del miedo prejuicioso, que, unido a los otros dos elementos que componen el prejuicio (esto es, el estereotipo y la propensión a las conductas hostiles), pueden dar lugar a comportamientos de violencia, discriminación u odio contra determinados colectivos, normalmente minoritarios, extranjeros o vulnerables. La historia alberga numerosos ejemplos de ello; así, durante la Peste Negra se desencadenaron en toda Europa explosiones de

7 J. DE LuCAS MARTín, «Prólogo», en AAVV, Igualdad de trato, prevención de la discriminación y delitos de odio en la Comunitat Valenciana, Valencia, Tirant lo Blanch, 2019, pp. 11-14.

${ }_{8}$ G. Allport, La naturaleza del prejuicio, Buenos Aires, Editorial Universitaria de Buenos Aires, 1971, p. 24.

9 R. C. Méndez Lorenzo y A. SuÁrez Martínez, «Capítulo 2. Estereotipos, prejuicios y discriminación. Una mirada desde la psicología social», en A. VIEDMA RojAS y C. DEL VAL CID (dirs.), Odio vs. derechos humanos: sociodiversidad, delitos y derechos, Madrid, Tecnos, 2019 , p. 49.

${ }^{10}$ Las clarificadoras palabras de Delumeau al respecto bien podrían aplicarse a la actual pandemia: «El prójimo es peligroso, sobre todo si la flecha de la peste ya le ha alcanzado; entonces, o bien se le encierra en su casa, o bien se le evacúa a toda prisa hacia algún lazareto situado fuera de las murallas. ¿Qué diferencia con el trato reservado en tiempos normales a los enfermos, a quienes padres, médicos y curas rodean con sus diligentes cuidados!». Vid. J. Delumeau, El miedo en Occidente, Madrid, Taurus, 2002, p. 180. 
odio antisemita, al acusarse a los judíos de querer envenenar a los cristianos a través de la peste. Así, entre 1348 y 1350 se produjeron pogromos en ciudades como Colonia, Stuttgart, Estrasburgo o Barcelona ${ }^{11}$. Por su parte, en Chipre encontraron un chivo expiatorio distinto al que culpar de la transmisión de la enfermedad: los esclavos musulmanes, muchos de los cuales serían asesinados ${ }^{12}$. Otra práctica común, que tendría lugar en los siglos posteriores, era la adjetivación de la epidemia en referencia a un país extranjero, al que se achacaba el origen de la enfermedad; así, la peste que se cernió sobre Lorena en 1627 se calificó de «húngara» y la que asoló a Toulouse en 1630 de «peste de Milán» ${ }^{13}$. Varios siglos después ocurriría lo mismo con la «gripe española» de 1918, que realmente no se había originado en este país.

Con todo, los extranjeros y las minorías religiosas no eran los únicos grupos sociales a los que se les imputaba la transmisión de la enfermedad. También los mendigos y los leprosos estaban en el punto de mira; así, a los primeros se les expulsaba de las ciudades en tiempos de epidemia, al considerarlos focos de contagio ${ }^{14}$; en cuanto a los segundos, al concebirse su enfermedad como un castigo divino, se les consideraba personas poco fiables y lujuriosas, susceptibles, por tanto, de contagiar a otros la peste ${ }^{15}$.

Por otra parte, no podemos dejar de mencionar el estigma al que se ve sometido el propio contagiado por la enfermedad. Para ello no es necesario retrotraernos a las epidemias de las Edades Media y Moderna. Basta con acercarnos a las reacciones sociales derivadas de la extensión a nivel mundial del Virus de la Inmunodeficiencia Humana (VIH) durante los años ochenta y noventa. Al tratarse de una enfermedad entre cuyas vías de transmisión se encontraban la práctica de relaciones sexuales (asociándose, sobre todo en las primeras décadas, al colectivo homosexual) y la inyección de drogas por vía intravenosa, los enfermos de SIDA han sido frecuentemente estigmatizados, imputándose su enfermedad a una supuesta vida promiscua y poco saludable. Asimismo, y dado el desconocimiento inicial acerca de la forma de transmisión de este virus, a esta concepción de los enfermos como culpables se le añadió el miedo a que pudieran transmitir la enfermedad en espacios públicos por vías como el contacto físico (estrechar la mano). Ello incrementó aún más la marginación social

${ }^{11}$ Ibid., p. 207.

${ }^{12}$ Ibid., p. 209

${ }^{13}$ Ibid., p. 208.

${ }^{14}$ Ibid., p. 206.

15 Ibid., p. 177. 
de los enfermos, hasta el punto de que era frecuente que personas probablemente seropositivas se negasen a someterse a las pruebas que permitían el diagnóstico de esta enfermedad para así no tener que cargar con el estigma asociado a ella ${ }^{16}$.

Desgraciadamente, la práctica totalidad de los prejuicios discriminatorios que acabamos de relatar se han reproducido durante la pandemia del coronavirus. En primer lugar, estos ataques se dirigieron contra las personas de nacionalidad china, como consecuencia del origen del virus en este país. La sinofobia se extendió a lo largo de Europa y Asia: algunos comercios de países como Japón o Corea del Sur vetaban la entrada de chinos en sus establecimientos ${ }^{17}$, mientras que en varios países occidentales, incluyendo España, se produjeron incidentes racistas como insultos o agresiones ${ }^{18}$. Asimismo, algunos líderes de extrema derecha españoles y estadounidenses, intentando sacar rédito de la situación, calificaron el Covid-19 de «virus chino» ${ }^{19}$, e incluso dieron pábulo a teorías de la conspiración acerca de un supuesto origen artificial del virus, creado, según esta postura, en un laboratorio chino con el objetivo de iniciar una guerra bacteriológica ${ }^{20}$. De esta forma, se repetían dos constantes históricas en las epidemias: la adjetivación de la enfermedad para asociarla a un país extranjero y la teoría de que la difusión de la enfermedad era deliberada (recordemos las acusaciones a los judíos de envenenar el agua). Ambas nacen de una raíz común: la dicotomía nosotros-ellos, esto es, la identificación del otro, del diferente, como un enemigo que amenaza nuestra sociedad y forma de vivir ${ }^{21}$.

${ }^{16}$ Sobre la estigmatización derivada del VIH vid. S. SonTAG, La enfermedad y sus metáforas. El SIDA y sus metáforas, Barcelona, Debolsillo, 2012, y J. BARBERO GUTIÉRREZ «SIDA y eutanasia. Más allá de la responsabilidad individual», en S. URRACA (ed.), Eutanasia boy. Un debate abierto, Madrid, Noesis, 1996, pp. 93-113.

17 E. Borreguero, «Virus», El País, 12 de febrero de 2020.

${ }^{18}$ En nuestro país, el Consejo para la Eliminación de la Discriminación Racial o Étnica, adscrito a la Secretaría de Estado de Igualdad, emitió una Recomendación con fecha 13 de abril de 2020 donde advirtió del aumento de insultos y agresiones racistas en el contexto de la pandemia. Dicha Recomendación se encuentra disponible en bttps://igualdad ynodiscriminacion.igualdad.gob.es/novedades/novedades/2020/pdf/Recomendacion-ConsejoCOVID19.pdf.

19 «La embajada china critica por racista a Ortega Smith tras hablar de "malditos virus chinos"», La Vanguardia, 14 de marzo de 2020, y «Coronavirus: Trump grilled on use of term "Chinese virus"», BBC, 18 de marzo de 2020.

20 A. MARS, «Trump carga contra China y vincula el virus a un laboratorio de Wuhan», El País, 1 de mayo de 2020.

${ }^{21}$ J. Padilla y P. Gullón, Epidemiocracia. Nadie está a salvo si no estamos todos a salvo, Madrid, Capitán Swing, 2020, pp. 117-125. 
Por otra parte, en esta ocasión también los contagiados y las personas con mayor riesgo de contagio fueron estigmatizados por un sector de la sociedad; por ello, algunos llegaron a instar e incluso a coaccionar a sus vecinos más expuestos al contagio por razón de su profesión (sanitarios, personal de los supermercados, etc.) a que abandonaran sus domicilios. Esta consideración del contagiado de coronavirus como un «apestado» se ha reflejado también en las sucesivas «olas» de transmisión de la pandemia; así, tuvo especial repercusión mediática el caso de una estudiante universitaria y enfermera en prácticas que, tras contraer la enfermedad, fue instada por sus compañeras de piso a que abandonara el mismo y se marchara a su municipio natal con sus padres, a pesar de que estos últimos eran personas de riesgo ${ }^{22}$.

A modo de conclusión, y sin desmerecer la inmensa solidaridad de la que dio muestras una buena parte de la población española durante los peores meses de la pandemia del coronavirus, lamentablemente se repitieron en ciertos sectores de la sociedad los mismos patrones discriminatorios de conducta que se observan en otros periodos de epidemias a lo largo de la historia. No obstante, la cuestión que pretendemos dilucidar ahora es si estas conductas pueden ser consideradas delito de incitación al odio, para lo cual primeramente debemos exponer sucintamente en qué consiste este concepto.

\section{APROXIMACIÓN CRÍTICA AL CONCEPTO DE DELITO DE INCITACIÓN AL ODIO DEL ART. 510 DEL CÓDIGO PENAL}

El delito que constituye el objeto de este trabajo se introdujo por primera vez en el ordenamiento jurídico español en 1995, con ocasión de la aprobación del nuevo Código Penal, vigente en la actualidad. El originario art. $510 \mathrm{CP}$, que traía causa de las atrocidades que en aquellos momentos se estaban cometiendo en la guerra de Yugoslavia y del auge de la violencia neonazi en nuestro país ${ }^{23}$, incluía únicamente dos apartados: el primero de ellos castigaba la provocación directa a la discriminación, la violencia o el odio contra grupos o asociaciones motivada por las

\footnotetext{
22 «Echan del piso a una estudiante de enfermería por dar positivo: "No tengo la necesidad de convivir con un Covid, para eso tienes tu casa"», $A B C, 23$ de noviembre de 2020.

23 J. A. DíAz LóPEz, El odio discriminatorio como agravante penal, Madrid, Civitas, 2013, pp. 30-31 y 41 .
} 
características comunes de los grupos protegidos (también llamados «grupos-diana») mencionados en el artículo ${ }^{24}$, mientras que el segundo hacía lo propio con las expresiones injuriosas y deliberadamente falsas que se proferían contra los mismos grupos o asociaciones del apartado anterior. Sin embargo, tras la aprobación por el Consejo de la UE de la Decisión Marco 2008/913/JAI, de 28 de noviembre de 2008, relativa a la lucha contra determinadas formas y manifestaciones del racismo y la xenofobia mediante el Derecho penal, urgía reformar el art. 510 para adaptarlo a lo dispuesto en dicha Decisión Marco, de obligado cumplimiento para los Estados miembros de la UE. Dicha reforma llegaría en 2015, con ocasión de las numerosas modificaciones que llevaría a cabo la Ley Orgánica $1 / 2015$, de 30 de marzo, en el Código Penal.

El nuevo art. 510, surgido de la reforma de 2015, incluye como sujetos pasivos a más grupos protegidos (concretamente, incluye la comisión del delito por motivos de género, diferenciándolo de los de sexo) y a los individuos que sufran las conductas castigadas en el artículo por razón de su pertenencia a esos grupos. Además, no se compone de dos, sino de seis apartados. El primero de ellos se divide a su vez en tres subapartados; así, el art. 510.1.a) castiga ahora no solo la incitación directa a la violencia, la discriminación, el odio y la hostilidad contra grupos o individuos, sino también la indirecta; el art. 510.1.b) castiga la difusión por cualquier medio, o incluso la tenencia con la finalidad de distribución, de material susceptible de incitar a las conductas señaladas en el subapartado anterior; en cuanto al art. 510.1.c), castiga la negación, enaltecimiento o trivialización de crímenes internacionales (esencialmente, genocidio, crímenes contra la humanidad y crímenes de guerra) contra los grupos protegidos o sus miembros cuando de esta manera se favorezca un clima de hostilidad hacia estos grupos. Todas estas conductas pueden ser castigadas con pena de prisión de hasta cuatro años.

En cuanto al segundo apartado del artículo, se trata de un subtipo atenuado que castiga, en su subapartado a), la humillación, menosprecio o descrédito que entrañen una lesión de la dignidad del grupo-diana o de algún miembro del mismo por razón de su pertenencia al grupo, y en su subapartado $b$ ), hace lo propio con el enaltecimiento de delitos distintos de los del art. 510.1.c) que se cometan contra estos grupos o sus miembros.

\footnotetext{
${ }^{24} \mathrm{El}$ artículo se refiere concretamente a la incitación al odio por motivos «racistas, antisemitas u otros referentes a la ideología, religión o creencias, situación familiar, la pertenencia de sus miembros a una etnia, raza o nación, su origen nacional, su sexo, orientación o identidad sexual, por razones de género, enfermedad o discapacidad».
} 
En cuanto a los apartados tercero y cuarto, recogen dos subtipos agravados que castigan con mayor pena (pudiendo llegar, en el caso del apartado 4 , a aumentarla un grado) las conductas recogidas en los apartados 1 y 2 cuando se cometan a través de medios de comunicación o tecnologías de la información (art. 510.3) o cuando resulten idóneos para provocar una alteración de la paz pública (art. 510.4).

Por último, los apartados quinto y sexto establecen, respectivamente, la inhabilitación especial para el ejercicio de profesión en el ámbito educativo para los autores de estos delitos, que puede prolongarse hasta diez años, y la destrucción o borrado de los archivos que sirvieran de soporte al material de odio.

El delito de incitación al odio, tal y como está regulado actualmente en nuestro ordenamiento jurídico, ha sido objeto de numerosas críticas doctrinales, de las que mencionaremos las más relevantes. En primer lugar, aunque el castigo de la incitación a la violencia y a la discriminación supone la protección de bienes jurídicos dignos de tutela en un Estado de derecho, no ocurre lo propio con el castigo de la incitación al odio strictu $s e n s u^{25}$, que también se encuentra tipificado en el artículo y que contraviene el viejo adagio latino cogitationes poenam nemo patitur («el pensamiento no delinque»). Además, la excesiva amplitud de los márgenes de las conductas típicas y la indeterminación de sus definiciones conculcan el principio de taxatividad penal ${ }^{26}$. A ello se le añade el excesivo adelantamiento de la barrera de protección penal que supone el castigo de la tenencia de material de odio cuando ni siquiera se ha comenzado con la distribución del mismo ${ }^{27}$. Finalmente, el castigo no solo de la incitación directa, sino también de la indirecta, resulta difícilmente compatible con el principio penal de ultima ratio ${ }^{28}$.

Antes de iniciar el estudio de cada caso concreto, queremos recalcar que, desde nuestro punto de vista, el delito de incitación al odio del art. 510 está orientado a la exclusiva protección de los grupos vulnerables,

${ }^{25}$ G. Portilla Contreras, «La represión penal del discurso del odio», en F. J. ÁlvareZ García (dir.), Tratado de Derecho Penal Español. Parte Especial. IV. Delitos contra la Constitución, Valencia, Tirant lo Blanch, 2015, p. 387.

${ }^{26}$ V. Gómez MarTín, Delitos de discriminación y discurso de odio punible. Nuevo escenario en España tras la LO 1/2015, Porto, Juruá, 2019, p. 132.

${ }^{27}$ J.-M. LANDA GoROSTIZA, «El discurso de odio criminalizado: propuesta interpretativa del art. 510 CP», en J.-M- Landa Gorostiza y E. Garro Carrera (dirs.), Delitos de odio: Derecho comparado y regulación española, Valencia, Tirant lo Blanch, 2018, pp. 234-237.

${ }^{28}$ R. AlCÁCer Guirao, La libertad del odio. Discurso intolerante y protección penal de minorias, Madrid, Marcial Pons, 2020, pp. 198-200. 
los cuales corren riesgo de que los mensajes proferidos contra ellos les puedan convertir en blanco de comportamientos discriminatorios ${ }^{29}$. Por ende, el fundamento del artículo viene dado por los efectos discriminatorios que puede llegar a provocar (discriminatory selection model) y no por la motivación del autor a la hora de cometer el delito (animus model) ${ }^{30}$, puesto que las expresiones con ánimo discriminatorio no pueden castigarse si no son idóneas ex ante para generar un peligro para los grupos protegidos, dado que, en caso contrario, serían totalmente inocuas. De hecho, el llamado Test de Rabat, establecido por el Plan de Acción de Rabat de Naciones Unidas de 2012, dirigido a la prohibición de la apología del odio nacional, racial o religioso, establece seis parámetros para determinar cuándo es perseguible el discurso del odio: el contexto, la influencia social del emisor del mensaje, la intención incitadora, el contenido del mensaje, su extensión y su probabilidad de provocar un daño a los grupos protegidos. En consecuencia, los mensajes que, en virtud de estos parámetros, sean inidóneos para poner en peligro al grupo no serán punibles. Esta interpretación restrictiva del delito de incitación al odio con la que nosotros nos identificamos permite corregir la dudosa compatibilidad del precepto con varios de los principios rectores del Derecho penal.

Nuestra posición, sin embargo, difiere de la mantenida por la Circular 7/2019, de 14 de mayo, de la Fiscalía General del Estado, sobre pautas para interpretar los delitos de odio tipificados en el art. 510 CP. Dicha Circular no restringe la aplicación del artículo a los grupos vulnerables, de manera que considera posible que los sujetos pasivos del delito de odio sean, por ejemplo, el colectivo heterosexual o incluso el colectivo neonazi, al que reconoce expresamente como grupo protegido.

Por último, queremos subrayar la necesidad de distinguir entre el delito de incitación al odio y cualquier otro delito cometido por una motivación discriminatoria. En este último caso, quien cometa dicha conducta será condenado como autor del delito de que se trate con la circunstancia agravante de odio discriminatorio del art. 22.4 CP, cuya lista de grupos protegidos es igual que la del art. $510 \mathrm{CP}$. Este sería el supuesto, ya mencionado, de quienes agredieron a miembros de la comunidad china culpabilizándoles de la llegada del virus. En tal caso, los autores de la agresión podrían ser condenados por un delito de lesiones con la concurrencia de

\footnotetext{
29 Por todos, R. AlCÁCER GuiRAo, «Diversidad cultural, intolerancia y Derecho penal», RECPC, núm. 18-11 (2016), p. 51.

30 M. Cancio Melía y J. A. Díaz López, ¿Discurso de odio y/o discurso terrorista? Música, guiñoles y redes sociales frente al art. 578 del Código Penal, Cizur Menor, Aranzadi, 2019, p. 71.
} 
la circunstancia agravante del art. 22.4 CP. Cabe destacar que este último precepto sí que responde al animus model, por lo que no será aplicable únicamente a grupos vulnerables.

\section{ANÁLISIS DE LOS CASOS}

\section{Carteles y pintadas contra los sanitarios}

El primer supuesto al que nos queremos referir en este artículo es el del hostigamiento a sanitarios y otros profesionales esenciales durante los meses más cruentos de la pandemia por parte de algunos de sus vecinos, que, temerosos del contagio, les instaban a marcharse de sus casas, normalmente a través de carteles pegados en la puerta de su vivienda o en las zonas comunitarias ${ }^{31}$. En ocasiones, estas conductas adquirieron incluso un cariz más agresivo, como en el caso de la ginecóloga de Barcelona Silvana Bonino, a quien pintaron en su coche (estacionado en el aparcamiento particular de la comunidad de vecinos) la frase «Rata contagiosa», además de pincharle las ruedas del vehículo ${ }^{32}$.

En relación con los mencionados carteles, la Policía Nacional advirtió de que los mismos podían constituir un delito de odio perseguible. En cuanto al autor de la pintada en el coche de la ginecóloga, fue denunciado por los Mossos d'Esquadra como autor de un delito de daños con la agravante de odio discriminatorio del art. 22.4 CP. Aunque este artículo, como ya hemos indicado, pretende centrarse esencialmente en las conductas que han sido objeto de denuncia, imputación o acusación por un delito de odio del art. $510 \mathrm{CP}$, creemos conveniente incluir también el caso de las pintadas en el vehículo. Ello se debe a que la calificación inicial de los Mossos d'Esquadra en la denuncia en ningún caso vincula posteriormente al Ministerio Público o a las acusaciones particulares en sus respectivos escritos de acusación ${ }^{33}$, donde razonablemente podrían solicitar una acusación por el art. $510 \mathrm{CP}$ de manera autónoma con respecto al delito de

31 «Los insolidarios mensajes de vecinos que piden a sanitarios y cajeras que se vayan de su casa para no contagiarse», La Vanguardia, 13 de abril de 2020.

32 «Silvana Bonino: una ginecóloga de Barcelona denuncia una pintada en su coche con el mensaje "Rata contagiosa"», El País, 15 de abril de 2020.

${ }_{33} \mathrm{Ni}$ siquiera vincula la calificación formulada por el juez de instrucción en el auto de transformación de las diligencias previas en procedimiento abreviado. Vid. J. BANACLOCHE PALAO, Aspectos fundamentales de Derecho procesal penal, Madrid, Wolters Kluwer, 2018, p. 248. 
daños, en vez de considerar el odio discriminatorio como una circunstancia agravante de este último.

Para determinar si, desde nuestro punto de vista, las conductas antes referidas pueden ser constitutivas de un delito de incitación al odio, debemos dilucidar, en primer lugar, si los sujetos pasivos de estas conductas (profesionales sanitarios y otros trabajadores esenciales) forman parte de los grupos protegidos o grupos-diana mencionados en el art. 510 CP. En principio, el único motivo discriminatorio de entre los contemplados en el artículo en el que hipotéticamente podría subsumirse la conducta es el de incitación a la violencia, discriminación u odio por razones de «enfermedad». Sin embargo, la cuestión no deja de suscitar varios interrogantes que expondremos a continuación.

En primer lugar, cabe preguntarse si este motivo discriminatorio se refiere a cualquier tipo de enfermedad. De acuerdo con la doctrina, la categoría de «enfermedad» en el art. 510 se refiere a aquellas patologías de carácter duradero que en cierto modo constituyen un elemento distintivo de la identidad del individuo ${ }^{34}$. En ello coincide la citada Circular 7/2019 de la FGE, que entiende que el motivo discriminatorio relativo a la «enfermedad» que aparece en el art. 510 se circunscribe «a la de carácter permanente o duradero». Desde nuestro punto de vista, sin embargo, lo verdaderamente relevante es la capacidad de la enfermedad de configurar la identidad de la persona, y no tanto el carácter crónico o duradero de esta. En consecuencia, aunque el Covid-19 no se puede considerar propiamente una enfermedad crónica ni duradera (como sí lo serían, por ejemplo, el cáncer y el SIDA), sí que goza de la suficiente entidad como para incidir notablemente, aunque sea de forma temporal, en la conformación de la identidad. Así, los autores de los carteles o de las pintadas contra los profesionales identifican a estos últimos con la enfermedad: ya no son personas ni trabajadores, sino «focos de contagio». Esta estigmatización derivada del Covid-19 no proviene tanto, como en otros casos, de una culpabilización al enfermo de su enfermedad, sino más bien del miedo al contagio, como ocurría en las epidemias de los siglos pasados. Y es precisamente dicha estigmatización la que, en nuestra opinión, provoca que esta enfermedad pueda ser motivo de discriminación, y, por ende, pueda subsumirse en el concepto de «enfermedad» contemplado en el art. 510 CP.

34 M. Cancio Meliá y J. A. Díaz López, ¿Discurso de odio y/o discurso terrorista?..., op. cit., pp. 83-84. 
La segunda cuestión que suscita polémica consiste en el hecho de que los profesionales frente a los que se han dirigido los carteles y pintadas no estaban necesariamente contagiados de Covid-19 cuando recibieron estos mensajes. En ello se amparan algunos juristas para afirmar que esos mensajes contra los profesionales solo podrían ser constitutivos de un delito de incitación al odio si estos estuvieran $\operatorname{contagiados}^{35}$. La respuesta a esta disyuntiva podría variar dependiendo de cuál se considera el fundamento de los delitos de incitación al odio: si entendemos que este radica en la motivación del autor de la conducta, sería irrelevante que la víctima estuviera contagiada o no, puesto que lo relevante no es tanto la condición de la víctima como el hecho de que el autor ha actuado movido por un afán discriminatorio por razones de enfermedad; si, por el contrario, consideramos que el fundamento del delito es la protección de determinados colectivos vulnerables (postura que, como ya hemos adelantado, es la que defendemos), en principio se podría afirmar que no puede formar parte de un colectivo vulnerable por razón de enfermedad alguien que ni siquiera está enfermo. Sin embargo, incluso desde este segundo punto de vista se podría sostener que la vulnerabilidad en el caso de los profesionales no viene dada por el hecho de estar contagiados, sino porque la mayor exposición al virus que tienen que padecer como consecuencia de su trabajo hace que sean estigmatizados como enfermos, lo cual, a su vez, es lo que motiva los mensajes vertidos contra ellos. De hecho, algunos de estos mensajes, como el de «Rata contagiosa», ya presuponen que los receptores del mensaje están contagiados de Covid-19. No se trataría, como podría aducir alguno para desvirtuar el carácter de grupo protegido de las víctimas, de un delito de odio «por razón de profesión», no tipificado en el art. 510, porque el motivo de los mensajes no es la condición de médicos, enfermeros o cajeros de los profesionales, sino la concepción prejuiciosa de los mismos como portadores de la enfermedad producida por el SARS-CoV-2. Muestra de ello es que, de no encontrarnos en un contexto de pandemia, estos mensajes en ningún caso se habrían proferido contra dichos trabajadores.

Desde esta perspectiva podemos afirmar que desde el discriminatory selection model, que para nosotros es el que impera en el art. $510 \mathrm{CP}$, la conducta se puede subsumir en un delito de incitación al odio por razones

35 Es la opinión del abogado Ricardo de Lorenzo preguntado al respecto por una revista destinada al colectivo médico («Coronavirus: el acoso a sanitarios no es delito de odio, pero sí coacción», Redacción Médica, 27 de abril de 2020). 
de enfermedad contra los profesionales más expuestos al coronavirus aunque estos no se encuentren contagiados.

La tercera y última cuestión consiste en dilucidar si los mensajes que aparecieron en los carteles o en las pintadas pueden subsumirse en alguna de las conductas previstas en el art. $510 \mathrm{CP}$, esto es, si incitan a la violencia, la discriminación, el odio o la hostilidad [art. 510.1.a)], o si entrañan humillación, menosprecio o descrédito hacia un grupo o miembro del mismo, lesionando la dignidad de los mismos [art. 510.2.a)]. A estos efectos, debemos distinguir entre aquellos mensajes en donde simplemente se sugería o se rogaba a los profesionales que buscasen otro lugar de alojamiento de aquellos en los que se les pretenda ordenar o imponer el abandono de su hogar, frecuentemente a través de expresiones injuriosas y amenazantes. Entendemos que los primeros, aunque sin duda son reflejo de un preocupante egoísmo desgraciadamente cada vez más extendido en nuestra sociedad, no constituyen ningún tipo de delito, dado que una sugerencia o petición nunca puede tener un carácter incitador. Respecto a los segundos (entre los cuales se encuentra, sin duda alguna, la pintada de «Rata contagiosa» en el automóvil de la ginecóloga), creemos que deben ser considerados como incitadores a la discriminación, y, por ende, podrían ser subsumibles, a priori, en el art. 510.1.a) CP.

Más complejo es determinar si esta incitación es, además, idónea ex ante para provocar una actuación contra los miembros del grupo protegido (profesionales susceptibles de estar enfermos o de enfermar). Por un lado, si tenemos en cuenta el clima de solidaridad masiva y apoyo a los sanitarios y demás trabajadores esenciales que se dio durante el primer estado de alarma, a priori ninguno de estos mensajes sería susceptible de influir en la sociedad, máxime si tenemos en cuenta que la autoría de estos mensajes no es imputable a personas influyentes en la sociedad, sino a individuos anónimos. Sin embargo, otros factores, como el pánico al contagio o la difusión de bulos que hacían referencia al carácter deliberado o planificado de la pandemia, también estaban presentes en este periodo y, combinados con estos mensajes, podrían, desde un punto de vista ex ante, haber abonado el terreno para la comisión de acciones violentas o discriminatorias contra estos profesionales. En definitiva, no podemos dilucidar a ciencia cierta si los mensajes podían tener un carácter incitador o no en el momento en que se emitieron. Esta falta de certeza nos conduce, irremediablemente, a defender que los autores de las pintadas y carteles que cargaban contra los sanitarios no puedan ser condenados por este delito, en virtud del principio favor libertatis que rige en el ordenamiento penal 
en general y en el ámbito de los delitos de odio en particular, recomendando la propia Circular 7/2019 la aplicación de este principio en los casos de duda. Ello no obsta, sin embargo, para que estos mensajes puedan ser constitutivos, a nuestro juicio, de otros delitos, como el de coacciones del art. 172.2 CP o incluso el de amenazas de los arts. 169 CP y ss.

\section{2. «Madrileñofobia» $\mathbf{y}$ «torrevejensefobia»: ¿delitos de odio?}

Los siguientes casos que vamos a abordar en este artículo se refieren a dos comentarios en redes sociales que fueron objeto de denuncias por delito de odio al considerarse vejatorios hacia los madrileños y torrevejenses. El primero de estos fue publicado por Clara Ponsatí, eurodiputada del partido independentista catalán Junts per Catalunya, quien, el día 15 de marzo de 2020, publicó en cuenta de Twitter el mensaje «De Madrid al Cielo» ${ }^{36}$, utilizando así el conocido refrán para hacer referencia a la elevada mortalidad por coronavirus que por aquel entonces se estaba produciendo en Madrid. La organización Movimiento contra la Intolerancia denunció el mensaje ante la Fiscalía al entender que «encajaba a la perfección en el art. 510.2 del Código Penal» al lesionar «la dignidad de los madrileños por razón ideológica en un contexto de extraordinaria gravedad». La denuncia, por tanto, entendía que la conducta era subsumible en el delito consistente en «lesionar la dignidad de las personas mediante acciones que entrañen humillación, menosprecio o descrédito de alguno de los grupos a los que se refiere el apartado anterior, o de una parte de los mismos, o de cualquier persona determinada por razón de su pertenencia a ellos». En cuanto al motivo de discriminación en este caso, entendía que era por razón de ideología ${ }^{37}$.

Lo primera pregunta que debemos resolver, como ya hicimos en el apartado anterior de este artículo, es si los madrileños son un grupo-diana de los mencionados en el art. 510 CP. Según los denunciantes, en este caso el delito de odio se cometía por razón de ideología, pero creemos que para ello sería necesario considerar a los madrileños como un colectivo «ideológico», esto es, con una ideología homogénea. No es suficiente, para enten-

\footnotetext{
36 «Ponsatí se burla de la situación del coronavirus en la capital: "De Madrid al cielo"», El País, 15 de marzo de 2020. El tuit fue borrado por su autora poco después, por lo que no podemos incluir aquí un enlace al mismo.

37 «Movimiento contra la Intolerancia denuncia ante la Fiscalía a Ponsatí y Puigdemont por el tuit de "De Madrid al cielo"», El Mundo, 16 de marzo de 2020.
} 
der cometido un delito de odio por motivos ideológicos, que el autor del mismo (en este caso, presuntamente, Clara Ponsatí) profiera el mensaje de odio contra el sujeto pasivo porque su ideología lo empuja a hacerlo, sino que resulta necesario que el mensaje se haya dirigido contra ese grupo o persona integrante del mismo porque conforman un colectivo que profesa una ideología distinta de la del receptor del mensaje. La jurisprudencia menor asume también esta interpretación; así, la SAP Segovia 23/2020, de 13 de marzo ${ }^{38}$, confirma la absolución de un individuo acusado de un delito de incitación al odio por proferir comentarios contra el torero fallecido Víctor Barrio, alegrándose de su muerte y afirmando que «bailaremos sobre su $[s i c]$ tumba y nos mearemos en las coronas de flores que te pongan, i¡cabrón!!». En esta resolución, en línea con lo afirmado en la sentencia dictada en primera instancia, se afirma que no puede entenderse cometido, como sostenía la acusación particular, un delito de odio por motivos de ideología, porque los profesionales y aficionados a la tauromaquia no conforman un colectivo ideológicamente homogéneo, sino que, por el contrario, agrupan a personas de muy diferentes sensibilidades ideológicas. Lo mismo podemos afirmar, en nuestro caso, respecto de los madrileños, entre los que incluso podemos encontrar partidarios del independentismo catalán que propugna Clara Ponsatí.

Por otra parte, y aunque no es esta la fundamentación del Movimiento contra la Intolerancia, debemos preguntarnos si podría existir un delito de incitación al odio por motivos de nacionalidad. Aunque en este caso tanto la autora como los destinatarios del mensaje comparten la misma nacionalidad (la española), parte de la doctrina considera aconsejable que dentro del término «nacionalidad» del art. $510 \mathrm{CP}$ se subsuman las diferentes identidades nacionales que existen, por razones históricas, en determinados Estados: sería el caso, por ejemplo, de la identidad catalana, gallega o vasca en España (las llamadas por la Constitución «nacionalidades históricas»). No nos convence del todo esta interpretación, puesto que desde nuestro punto de vista es demasiado extensiva y entraña problemas conceptuales de difícil solución, tales como determinar cuál es el límite con respecto a las identidades nacionales dentro de un mismo Estado o por qué se debe reconocer la identidad catalana y no, en cambio, la andaluza o castellana ${ }^{39}$. Solo vemos factible dicha diferenciación en aquellos países

\footnotetext{
38 SAP Segovia 23/2020, de 13 de marzo (Id. Cendoj: 40194370012020100038).

39 Sí que se admite, en cambio, en M. Cancio Melí́ y J. A. Díaz López, ¿Discurso de odio y/o discurso terrorista?..., op. cit., p. 81.
} 
en los que, a diferencia de España, existan minorías nacionales ${ }^{40}$, como los kurdos en Turquía y los chechenos en Rusia ${ }^{41}$. Pero, incluso si asumiéramos que existen diferentes identidades nacionales dentro de nuestro país, en ningún caso podemos reconocer la existencia de una «identidad nacional madrileña» diferente de la española. Por tanto, tampoco se puede afirmar que existe un delito de odio por razón de nacionalidad.

En definitiva, como el mensaje de Ponsatí no se dirige contra ninguno de los grupos protegidos en el art. $510 \mathrm{CP}$, en ningún caso es subsumible en este tipo penal. Pero, desde nuestro punto de vista, tampoco lo sería si los madrileños fueran un grupo protegido por el artículo. Esto se debe a que la frase del tuit no deja de ser un mensaje de humor negro que, aunque deleznable y de pésimo gusto, no goza de la suficiente entidad como para considerarse lesivo de la dignidad. Por tanto, en modo alguno podría considerarse un delito de odio del art. 510.2 CP.

El segundo de los casos a analizar es el de un individuo, supuestamente proveniente de Madrid, que se encontraba en Torrevieja y que fue detenido el día 10 de abril de 2020 por la Guardia Civil como consecuencia de un vídeo colgado en sus redes sociales en los días anteriores donde sostenía que había viajado expresamente desde Madrid hasta allí a contagiar el virus a los torrevejenses. Tras asegurar que había desvalijado un supermercado junto con otros miles de madrileños con el objetivo de provocar la carestía en la localidad, afirmaba literalmente: «Os vamos a contagiar el virus. Para que os den por culo, que estamos hasta los cojones de todos los de Torrevieja, para que os jodáis. A tomar por culo todos los de Torrevieja,

${ }^{40}$ Entendiendo como minoría nacional de Capotorti, Relator Especial de la Subcomisión de Prevención de la Discriminación y Protección de las Minorías de Naciones Unidas, en su Informe sobre derechos de las minorías de 1979: «Un grupo numéricamente inferior al resto de la población de un Estado, en situación no dominante, cuyos miembros, súbditos del Estado, poseen desde el punto de vista étnico, religioso o lingüístico unas características que difieren de las del resto de la población y manifiestan, incluso de modo implícito, un sentimiento de solidaridad con el objeto de conservar su cultura, sus tradiciones, su religión o su idioma» (citado en J. M. Contreras Mazarío, Las Naciones Unidas y la protección de las minorías religiosas: la tolerancia a la interculturalidad, Valencia, Tirant lo Blanch, 2004, pp. 159-160). Sobre la noción actual de minoría, vid. también F. Amérigo Cuervo-ArAngo, «Presentación», en AAVV, Cuadernos de Estrategia 200. Globalización e identidades. Dilemas del siglo XXI, Madrid, Ministerio de Defensa, 2019, pp. 7-16, y A. G. LóPEZ MarTín, «Las minorías en el contexto actual: una aproximación a su marco jurídico internacional», en A. G. López Martín y C. Otero García-Castrillón (dirs.), Las minorías en el contexto actual, Madrid, Dykinson, 2020, pp. 13-26.

${ }^{41}$ En el caso de España se ha planteado, lege ferenda, el reconocimiento del pueblo gitano como minoría nacional. Vid. F. VILlarReAL, El reconocimiento institucional de la comunidad gitana en España, Madrid, Fundación Secretariado Gitano, 2006. 
que os den por culo, que soy de Madrid y que os jodan. A la mierda» ${ }^{42}$. Al ser puesto a disposición ante el Juzgado de Instrucción núm. 1 de Torrevieja, el magistrado Miguel Ángel González Felipe acordó por medio de auto la libertad provisional del individuo porque el Ministerio Fiscal no había solicitado la prisión provisional, pese a que, según expresó en el propio auto, entendía que en este caso procedía dicha medida cautelar al existir suficientes motivos para considerar al imputado responsable de los hechos que se le atribuyen (fumus delicti comissi, exigido por el art. 503.1.2. ${ }^{\circ}$ LECrim.) y apreciarse tanto riesgo de fuga como de reiteración delictiva (periculum in mora, en virtud del art. 503.1.3. ${ }^{\circ}$ LECrim.). El magistrado impuso al autor del vídeo la medida cautelar de prohibición de visitar o residir en el municipio de Torrevieja, retirándole asimismo el pasaporte. Además, sostuvo en el auto que los hechos incitan al odio hacia los torrevejenses, alterando así la paz pública y menospreciando además a los enfermos de Covid-19 13 .

Desde nuestro punto de vista, los torrevejenses no son un grupo protegido por el delito de odio, dado que, en línea con lo expuesto anteriormente para el caso de Clara Ponsatí, no existe en dicha localidad una suerte de «identidad nacional torrevejense» diferente de la española. Por otra parte, el mensaje no tiene como blanco de sus ataques a los enfermos por Covid-19, por lo que en ningún caso estos pueden constituir el sujeto pasivo. Esta habría sido ya una razón suficiente para que el juez de instrucción no iniciara ningún procedimiento penal como consecuencia de la denuncia, dado que el hecho objeto de la misma no constituía delito. No obstante, al argumento anterior se le añade el hecho de que las expresiones vertidas en el vídeo, sin duda desafortunadas y esperpénticas, no generan ex ante un riesgo de que se produzcan acciones contra los habitantes de Torrevieja: en primer lugar, el individuo que emite el mensaje no ostenta ningún tipo de estatus o posición social que le convierta en alguien influyente ante sus oyentes (líder político, religioso, de opinión, etc.), y, en segundo lugar, los torrevejenses no son un colectivo susceptible de ser blanco de ataques violentos o discriminatorios ni por parte de la población madrileña ni de ninguna otra, en tanto que nunca han existido comportamientos de esta índole contra los habitantes de esta localidad ni existe ningún factor que haga pensar que se pueden producir en el futuro. Es por

\footnotetext{
${ }^{42}$ El vídeo completo está disponible en el canal oficial de YouTube de la Guardia Civil: bttps://www.youtube.com/watch?v=V63gEVUu-QI.

${ }^{43}$ Auto del Juzgado de Instrucción núm. 1 de Torrevieja de 11 de abril de 2020 (Diligencias previas 551/2020) (Id. Cendoj: 03133430012020200002).
} 
ello que la referencia a la alteración de la paz pública que realiza el juez de instrucción carece de justificación a la luz de nuestro ordenamiento: dicha alteración no es, per se, un elemento del tipo penal del delito de odio (a diferencia de lo que ocurre en otros países de nuestro entorno, como Alemania $)^{44}$, sino que solo será penalmente relevante cuando genere un riesgo de actuaciones contra los miembros del grupo protegido. Por ende, incluso aunque el hecho de que numerosos habitantes de la localidad llamasen alarmados a las autoridades se considerase un reflejo de la alteración de la paz pública, ello no influye a la hora de determinar si nos encontramos ante un delito de incitación al odio.

En agosto de 2020, y tras la aportación de un informe por parte de la Fiscalía en donde se alegaba que los hechos no podían ser considerados como un delito de odio, el juez de instrucción núm. 1 de Torrevieja archivó la causa, reconociendo, además, el animus iocandi o carácter jocoso que tenía el vídeo ${ }^{45}$. Desde nuestro punto de vista, el juez debería haberse percatado desde un primer momento de que el vídeo carecía de relevancia penal, de modo que en ningún momento se tendría que haber procedido a la apertura de diligencias previas y mucho menos a la imposición de medidas cautelares.

\section{La humillación a una mujer transexual en Benidorm}

El siguiente supuesto que vamos a analizar es el de una mujer transexual que fue objeto de insultos humillantes por parte de un agente de policía. Este, que iba en un coche patrulla junto con un compañero, espetó a la víctima lo siguiente: «De día eres todavía más feo, eres horrible. ¿Qué hacéis ahora que no podéis jalar pollas ni robar? ¿Cómo vives? Si antes jalarías pocas pollas, con lo feo que eres, ¿ahora qué haces? ${ }^{46}$. Los hechos fueron grabados por su compañero de patrulla. El agente que

${ }^{44}$ Sobre el delito de incitación al odio en Alemania, vid. E. Garro Carrera, «Los discursos de odio en el ordenamiento jurídico penal alemán: el "laberinto dogmático" del tipo de incitación a la población del 130 StGB», en J.-M. LANDA Gorostiza y E. Garro CarReRA, Delitos de odio: Derecho comparado y regulación española, Valencia, Tirant lo Blanch, 2018, pp. 27-78.

45 «No hay "odio" en el hombre que aseguró que iría a Torrevieja a expandir el coronavirus», EFE, 25 de agosto de 2020. No nos consta la presencia de dicho auto en el repertorio jurisprudencial del Centro de Documentación Judicial (CENDOJ).

46 «¿Qué hacéis ahora que no podéis jalar pollas?”: dos policías humillan a una transexual», Clm24.es, 1 de mayo de 2020. 
había proferido los insultos fue detenido por un presunto delito de incitación al odio, mientras que a su compañero se le imputó un delito de omisión del deber de socorro por no haber intentado impedir el comportamiento del otro policía ${ }^{47}$.

Como ya hemos hecho en los apartados anteriores, para dilucidar si en efecto se cometió en este caso un delito de odio debemos determinar primeramente si la víctima puede encuadrarse dentro de un grupo protegido. En este caso, no hay duda de que así es, porque el delito de odio por razones de identidad sexual se encuentra contemplado en el art. 510 CP. Como ha señalado tanto la doctrina como la Circular 7/2019, el término «identidad sexual» se refiere a la forma de cada persona de definirse sexualmente a sí misma, independientemente de cuál sea su sexo biológico. Por tanto, las personas transexuales encajan a la perfección en este concepto.

Tras haber determinado que la víctima forma parte de uno de los grupos-diana del art. 510, debemos dilucidar si las palabras proferidas por el agente de policía pueden incardinarse en alguna de las conductas penadas por este artículo. En concreto, nos preguntamos si es subsumible en el apartado 2 del citado artículo, esto es, si la conducta lesiona la dignidad de esa persona porque supone una humillación, menosprecio o descrédito hacia ella por su condición de transexual. Si nos fijamos en las expresiones utilizadas por el agente para insultar a la mujer, podemos afirmar que guardan relación con la identidad sexual de esta última; así, le dice que es «feo», utilizando deliberadamente el masculino para recalcar que no es realmente una mujer, y le atribuye la conducta de «jalar pollas», ridiculizando así sus preferencias sexuales, preferencias que además vincula a su transexualidad. Hay quien podría alegar, para contrarrestar este argumento, que esas expresiones no evidencian una animadversión a la víctima por su condición de transexual y que, de no haberlo sido, el agente habría utilizado exactamente las mismas expresiones contra ella, por lo que la conducta debería considerarse, a lo sumo, un delito de injurias. No estamos de acuerdo con esta postura, puesto que entendemos que el policía ha elegido precisamente esos insultos y no otros porque se dirigía a una persona transexual: las expresiones escogidas, como acabamos de explicar, están estrechamente vinculadas a la identidad sexual de la víctima.

Por último, debemos analizar si dichos mensajes eran susceptibles de provocar un peligro para el colectivo transexual. En este caso, el contex-

47 «Detenido por delito de odio el policía local que vejó a una persona trans en Benidorm», El País, 1 de mayo de 2020. 
to de pandemia no influye en modo alguno en el mensaje, lo que en principio reduciría su peligrosidad. Sin embargo, el hecho de que el autor de esas expresiones fuera un funcionario público, así como la filmación de la escena para su difusión, constituyen dos elementos que agravan la conducta hasta el punto de convertirla, a nuestro juicio, en delictiva. En consecuencia, entendemos que en este caso sí se cometió un delito de incitación al odio del art. $510.2 \mathrm{CP}^{48}$.

\section{La vejación al dueño de un bazar chino}

El 10 de mayo de 2020, la Policía local de Sevilla denunció por un presunto delito de incitación al odio a un joven de veintisiete años que había colgado en sus redes sociales un vídeo en el que aparecía insultando a un individuo de origen chino que regentaba un establecimiento de alimentación, espetándole, entre otras expresiones injuriosas, que «tenía coronavirus». En el rótulo que aparecía sobre el vídeo, el joven indicaba que «esto es lo que le pasa al chino cuando no me fía cinco céntimos después de estar mes y medio cerrado».

Lo primero que debemos dilucidar, al igual que en los casos anteriores, es si la víctima pertenecía a un grupo protegido por el art. 510 CP. Dado que se trataba de un ciudadano de origen chino, es encuadrable, sin duda alguna, en el grupo protegido por su pertenencia a determinada raza o nación.

En cuanto a si la conducta coincide con alguna de las modalidades del art. 510, nuevamente nos encontramos, como en el caso anterior, ante una conducta que puede incardinarse a la perfección en el apartado segundo del artículo, pues el autor del vídeo utiliza una serie de expresiones humillantes hacia el dueño del establecimiento que vienen motivadas por el origen chino del mismo, como la afirmación de que tiene coronavirus, en referencia a la condición de China de foco originario de la pandemia. De hecho, en el propio mensaje que acompaña a la grabación se refiere al destinatario de los insultos como «el chino», lo que refuerza aún más nuestro argumento.

Por último, y respecto a si el mensaje es idóneo ex ante para poner en peligro al colectivo protegido, nuestra respuesta también debe ser afirmativa: como hemos explicado al principio de este artículo, la comunidad china

48 No obstante, algunos autores consideran preferible calificar estas conductas de delito de injurias con la circunstancia agravante del art. $22.4 \mathrm{CP}$, al entender que, cuando la expresión se profiere cara a cara, es más una injuria que una incitación. Vid. R. ALCÁCER GUIRAO, La libertad del odio..., op. cit., p. 235 
fue una de las más azotadas por los brotes xenófobos que la pandemia trajo consigo e incluso en algunos lugares de España los ciudadanos de origen chino fueron objeto de agresiones físicas, por lo que mensajes como el de este joven sevillano eran susceptibles, en este contexto, de calar en algunos sectores de la sociedad. Por otra parte, y a pesar de la insignificancia social del autor de los mensajes, el hecho de que subiera el vídeo a sus redes sociales favoreció indudablemente la difusión del mensaje, lo que incrementa el peligro para el colectivo diana. En conclusión, consideramos que el autor del vídeo cometió un delito de incitación al odio del art. 510.2 CP.

\section{Delitos de odio por motivos ideológicos}

El presente apartado estará dedicado al análisis de cuatro supuestos concretos, todos ellos acontecidos durante los primeros meses de la declaración del estado de alarma, con el propósito de aclarar si los mismos pueden subsumirse en un delito de odio por motivos ideológicos.

Así, el primer supuesto que estudiaremos trae causa de la publicación de un tuit desde la cuenta oficial de Vox en Twitter. En dicho tuit, publicado en una de las semanas más duras de la pandemia, se reproducía un fotomontaje de la Gran Vía de Madrid repleta de féretros arropados con la bandera de España. La imagen aparecía, además, acompañada del siguiente mensaje: «esta [en referencia a la imagen] retrata perfectamente el dolor de esta tragedia que el Gobierno y sus satélites mediáticos pretenden ocultar». Este mensaje fue puesto en conocimiento de la Fiscalía mediante una denuncia presentada por parte del Partido Socialista, en tanto que esta formación consideraba que aquel podía resultar constitutivo de un delito de odio contra los miembros del Gobierno ${ }^{49}$. La Fiscalía rechazaría empero que este mensaje, así como otros de contenido similar publicados desde la cuenta oficial de Vox y que fueron asimismo añadidos a la presente denuncia, pudiera ser subsumido en alguna de las conductas recogidas en el art. $510 \mathrm{CP}^{50}$.

El segundo caso que nos gustaría comentar tiene como protagonista a un exmiembro de las Fuerzas Armadas simpatizante de grupos de extrema derecha. Este exmilitar aparece en un vídeo difundido en las redes socia-

\footnotetext{
49 «El PSOE denuncia ante la Fiscalía a Vox por difundir bulos», El País, 16 de abril de 2020.

50 «Archivada la denuncia del PSOE contra Vox por tuits contra el Gobierno por “ocultar" fallecidos», El Español, 30 de septiembre de 2020.
} 
les disparando con una escopeta contra fotografías de varios miembros del Gobierno, concretamente de su presidente, Pedro Sánchez; su vicepresidente segundo, Pablo Iglesias; el ministro del Interior, Fernando GrandeMarlaska, y la ministra de Igualdad, Irene Montero; así como del portavoz del Grupo Parlamentario Confederal de Unidas Podemos en el Congreso, Pablo Echenique. Aunque estos hechos tuvieron lugar en una galería privada de tiro situada en la provincia de Málaga y solo fueron presenciados por tres personas más, la escena, grabada y difundida por grupos de Whatsapp, sería posteriormente viralizada en las redes sociales por parte de terceros a modo de denuncia de dicha conducta. Esto acabaría determinando la detención del autor de los disparos por la Guardia Civil. Si bien el sujeto fue puesto en libertad tras prestar declaración en la Comandancia de la Guardia Civil de Málaga, el Gobierno decidió dar traslado a la Fiscalía de los hechos por si estos resultaban constitutivos de delito. ${ }^{51}$ Aunque los hechos han sido investigados por la Fiscalía no solo como un delito de odio, sino también como un delito contra las instituciones del Estado ${ }^{52}$ (delito este último que ha sido recientemente sobreseído por auto del Juzgado Central de Instrucción núm. 5 de la Audiencia Nacional), aquí nos centraremos en su análisis como un presunto delito de odio.

El tercer supuesto que queremos abordar es el que afecta a la periodista Cristina Seguí, quien, entre los días 29 de marzo y 16 de abril, publicó una serie de tuits en los que tachaba a los miembros del Gobierno de «criminales», «mengueles» o «mataviejas», refiriéndose incluso al presidente del Gobierno como «miserable» y «cerdo sinvergüenza». El Partido Socialista puso entonces en conocimiento de la Fiscalía la existencia de estos tuits, considerando que los mismos podían resultar constitutivos no solo de un delito contra las instituciones del Estado, sino también de un posible delito de odio ${ }^{53}$. Por su parte, la Fiscalía entendió que, a la luz de la situación social derivada como consecuencia de la pandemia y de la reiterada actitud crítica asumida por la periodista respecto de la gestión sanitaria del Gobierno, los mensajes, sin perjuicio de que pudieran resultar «irrespetuosos» e «insultantes», no comportaban una «cosificación» o «deshumaniza-

51 «Detenido en Málaga el exmilitar identificado como autor de los disparos a las fotos de miembros del Gobierno», Europa Press, 19 de junio de 2020.

52 Las actuaciones del delito contra las instituciones del Estado (art. 504 CP) han sido recientemente sobreseídas por auto del Juzgado Central de Instrucción núm. 5 de la Audiencia Nacional. Vid. «Archivada la causa contra el exmilitar que disparó a fotografías de miembros del Gobierno», 20 minutos, 9 de febrero de 2021.

53 «El PSOE denuncia a la tertuliana y analista Cristina Seguí», Infolibre, 23 de abril de 2020. 
ción» de un colectivo protegido por el art. $510 \mathrm{CP}$ ni resultaban incitadores al odio, hostilidad, discriminación o violencia ${ }^{54}$.

Respecto al primero de los supuestos reseñados, cabe indicar que el mensaje publicado desde la cuenta oficial de la formación política Vox en Twitter se enmarca en una estrategia política consistente en realizar una crítica áspera y severa a la gestión de la pandemia por el Gobierno, en contraste con la unidad de acción de los poderes públicos que reclamaban nuestros sanitarios y otros trabajadores de la denominada como «primera línea» (expresión esta que da muestra, una vez más, de la asunción de un lenguaje belicista para referirnos a la pandemia). Dicho lo cual ha de señalarse que el mensaje no reúne en modo alguno los elementos tipificados en los apartados del art. $510 \mathrm{CP}$. Al margen de que el destinatario del mensaje, esto es, el Gobierno, no constituya un grupo colectivo protegido a los efectos del mencionado precepto, resulta cuando menos discutible que el mensaje fuese proferido contra un grupo ideológicamente homogéneo. Es preciso recordar que, por vez primera en nuestra historia constitucional reciente, el Gobierno no se encuentra conformado por militantes o simpatizantes de un único partido político, sino que sus miembros pertenecen o son próximos a tres formaciones políticas distintas - PSOE, Podemos e Izquierda Unida-, que defienden, al menos, dos ideologías distintas como son el socialismo y el comunismo, las cuales, aunque incardinadas ambas en el espectro político de la izquierda, albergan hondas diferencias entre sí. Esta circunstancia, derivada de la implosión del modelo bipartidista en nuestro país, impide que en la actualidad podamos hablar de unidad ideológica de los miembros del Ejecutivo. De sostenerse que el mencionado tuit fue publicado con la intención de incitar al odio contra un determinado colectivo ideológico, habría que concretar, pues, de forma indubitada la ideología en cuestión que resulta amenazada por la emisión del mensaje, tarea esta que resulta de tremenda complejidad debido a las diversas sensibilidades ideológicas que conviven en el seno del Consejo de Ministros.

Lo afirmado respecto de este caso es perfectamente trasladable a los otros dos supuestos referidos; así, en el caso de Cristina Seguí las expresiones también se dirigían contra el Gobierno, sin perjuicio de que tuvieran un carácter más grosero que el de los tuits de Vox, circunstancia que empero no influye en la irrelevancia penal de su conducta. En lo que se

54 «Fiscalía archiva la denuncia del PSOE por injurias y odio contra Cristina Seguí», El Confidencial, 29 de octubre de 2020. 
refiere al caso del autor de los disparos contra las fotografías del Gobierno, la atipicidad de su comportamiento, que se puede considerar una forma de expresión no verbal, dado el carácter simbólico de los disparos, no solo radica en los argumentos que ya hemos explicado, sino también en que no consta que el autor de la conducta ni sus tres acompañantes participaran en la difusión del vídeo a través de redes sociales, limitándose a colgarlo en un grupo privado de Whatsapp.

En los tres supuestos analizados se refleja la tendencia de utilizar el delito de incitación al odio como mecanismo de protección de las instituciones, objetivo que difiere totalmente de la finalidad originaria del delito de odio y que desvirtúa su contenido, convirtiéndolo en un instrumento de judicialización del debate político que trae consigo el nada deseable efecto desaliento (chilling effect), frente al que tantas veces ha prevenido la jurisprudencia de Estrasburgo.

El cuarto supuesto que vamos a analizar en el marco de la incitación al odio por motivos ideológicos difiere de los anteriores. Centrándonos primero en el contexto de los hechos, debemos indicar que durante la segunda quincena de mayo, cuando el confinamiento domiciliario se había mitigado y se permitía pasear o correr por la calle durante determinadas horas y con ciertas restricciones, se sucedieron en todo el territorio nacional diferentes concentraciones y manifestaciones de distinto signo ideológico. Una de las situaciones más tensas que se vivieron en el transcurso de estas protestas fue en el distrito de Moratalaz, donde se produjo una pequeña trifulca entre manifestantes de uno y otro signo que se saldó con un total de cinco manifestantes de izquierda denunciados por un delito de lesiones y otro de odio, presuntamente cometidos contra un individuo de ideología distinta a la suya ${ }^{55}$. Sin entrar a analizar el delito de lesiones, así como la posible aplicación de una eximente completa o incompleta de legítima defensa ${ }^{56}$, nos centraremos en el delito de odio.

De nuevo comenzaremos dilucidando si el sujeto pasivo coincide con alguno de los colectivos protegidos en el art. $510 \mathrm{CP}$. La respuesta, en principio, debe ser afirmativa, puesto que, a diferencia de los supuestos anteriores, el presunto sujeto pasivo no es una institución ni un partido político, sino un ciudadano que supuestamente profesa una determinada

55 «Una pelea durante las caceroladas contra el Gobierno deja un herido leve en Madrid», Onda Cero, 21 de mayo de 2020.

56 Esto último ocurriría si se demostrara que la agresión inicial provino del grupo de manifestantes de derecha, tal y como parece que podría deducirse de algunas grabaciones existentes de los hechos, si bien ninguna de estas cuestiones ha sido dilucidada todavía en sede judicial. 
ideología (de derechas, concretamente), lo que a priori podría motivar la aplicación al caso del delito de incitación al odio por motivos ideológicos. Todo ello sin perjuicio de nuestras reticencias a que el delito de odio proteja a grupos ideológicos, pues ninguno de ellos, al menos en España, puede calificarse como grupo vulnerable.

Aunque el sujeto pasivo coincida con el previsto para el delito de incitación al odio, no ocurre lo mismo con la conducta denunciada, que en ningún caso es subsumible en el mismo. Dicha conducta consistió supuestamente en un acometimiento físico y no en una expresión incitadora, por lo que no es aplicable a ella un delito de expresión, como lo es el delito de odio. En consecuencia, consideramos que no procedía la denuncia por el delito del art. 510.

\section{CONCLUSIONES}

Una vez analizados los casos anteriores, podemos concluir que la aplicación del delito de incitación al odio del art. 510 CP durante el primer estado de alarma no se ajustó, en líneas generales, al contenido y finalidad de dicho precepto.

Sin embargo, no sería justo imputar únicamente esta desnaturalización del delito de odio al contexto jurídico de excepción que ha caracterizado a los primeros meses de la pandemia. Este tan solo ha agudizado las malinterpretaciones del delito de incitación al odio que ya se encontraban presentes en la práctica jurídica desde hacía años, concretamente desde la reforma de este delito en 2015.

La primera de estas tergiversaciones trae causa de considerar que este delito es aplicable a colectivos no vulnerables e incluso a colectivos que no están expresamente previstos en el art. 510, práctica esta última que constituye un incumplimiento flagrante del principio de legalidad penal. Nada nos dice dicho precepto acerca de los habitantes de determinado municipio, y, sin embargo, hemos observado cómo se han formulado denuncias por un supuesto delito de odio cometido contra madrileños y torrevejenses, lo cual alcanza el cénit del absurdo. Por otra parte, el empleo de este delito para proteger a instituciones del Estado, las cuales, lógicamente, no sufren vulnerabilidad alguna, ha convertido muchas veces el delito de odio en un instrumento de represión de la crítica política, a pesar de que esta, en tanto que garante del mantenimiento de una sociedad democrática, debería gozar de especial protección. 
El segundo problema que subyace a la aplicación del delito radica en el olvido de que, conforme al principio de ultima ratio, solo los casos más extremos de discurso del odio deberían ser penalmente punibles. Así, la interpretación restrictiva del delito que nos exige este precepto conlleva el castigo únicamente de aquellas conductas que realmente sean capaces ex ante de prender la llama del odio en la sociedad, suscitando comportamientos violentos o discriminatorios contra los miembros de los grupos protegidos. En consecuencia, las conductas vejatorias de un miembro de las Fuerzas y Cuerpos de Seguridad del Estado hacia una ciudadana transexual o la difusión por redes sociales de un vídeo en el que se humilla, por su origen nacional, al dueño de un establecimiento, en principio se podrían subsumir en el delito de odio, pero en ningún caso podemos hacer lo propio con un vídeo donde un presunto madrileño amenaza a los habitantes de Torrevieja con contagiarlos a todos y vaciar sus establecimientos, dado que las posibilidades de que un mensaje de esta índole pueda mover voluntades son nulas.

Para finalizar, frente a quienes abogan por «aplastar la serpiente en el huevo» ${ }^{57}$ para acabar con la discriminación y el odio, empleando la vía punitiva antes de tiempo, nosotros abogamos por impedir que «la serpiente» nazca, lo que se consigue mediante recursos extrajurídicos, tales como la adopción de medidas contra la discriminación de las minorías, la educación en valores como la solidaridad y el respeto mutuo, y el acceso de los grupos vulnerables a los medios de comunicación, desde donde pueden contrarrestar los discursos del odio. Solo cuando, a pesar de todo ello, el huevo se resquebraje y la serpiente asome la cabeza, será legítimo aplastársela blandiendo el Código Penal.

${ }^{57}$ M. MARTínez Sospedra, «Aplastar la serpiente en el huevo», Revista General de Derecho, núm. 664-665 (2000), pp. 99-116. 